\title{
Erratum to: GLP-1-dependent and independent effects and molecular mechanisms of a dipeptidyl peptidase 4 inhibitor in vascular endothelial cells
}

Yunshan Hu • HongBin Liu • Richard W. Simpson • Anthony E. Dear

Published online: 28 December 2012

(C) Springer Science+Business Media Dordrecht 2012

\section{Erratum to: Mol Biol Rep}

DOI 10.1007/s11033-012-2290-8

This erratum is published as there were discrepancies related with author names in the original publication.
Author names should now be read as:

Yunshan Hu, HongBin Liu, Richard W. Simpson and Anthony E. Dear.

The online version of the original article can be found under doi:10.1007/s11033-012-2290-8.

Y. Hu $\cdot$ H. Liu $\cdot$ A. E. Dear $(\square)$

Eastern Clinical Research Unit, Translational Research Division, Department of Medicine, Australian Centre for Blood Diseases, Monash University, 89 Commercial Rd., Prahran 3181,

Melbourne, VIC, Australia

e-mail: anthony.dear@monash.edu

R. W. Simpson · A. E. Dear

Department of Medicine, Eastern Clinical School, Monash

University, Level 2, 5 Arnold Street Box Hill 3128,

Melbourne, VIC, Australia

R. W. Simpson

Department of Endocrinology, Eastern Health, Level 2,

5 Arnold Street Box Hill 3128, Melbourne, Australia 